УДК $37.015 .3+159.9$

DOI 10.37386/2413-4481-2020-1-58-64

Г.С. Корытова

ПСИХОЛОГО-ПЕДАГОГИЧЕСКИЕ УСЛОВИЯ ПРОФИЛАКТИКИ
ПРОФЕССИОНАЛЬНОГО ВЫГОРАНИЯ В ОБРАЗОВАТЕЛЬНОЙ СРЕДЕ1

В статье определены психолого-педагогические условия профилактики эмоционального выгорания в профессиональной педагогической деятельности. Обсуждаются результаты апробации психопрофилактической программы, направленной на предупреждение выгорания у участников балинтовской группы педагогов.

Ключевые слова: эмоциональное выгорание, психопрофилактика, педагогические работники, образовательная среда.

\title{
G.S. Korytova
}

\section{PSYCHOLOGICAL AND PEDAGOGICAL CONDITIONS OF PROFESSIONAL BURNOUT PREVENTION IN EDUCATIONAL ENVIRONMENT}

In the article we determine psychological and pedagogical conditions of emotional burnout prevention in professional pedagogical activities. We discuss the results of preventative program approbation. The program was applied to the educators who participated in Balint group.

Key words: emotional burnout, psychological prevention, pedagogues, educational environment

Проблема эмоционального выгорания, возникающего в процессе выполнения педагогами профессиональной деятельности, при всем разнообразии работ зарубежных, а в последние десятилетия и отечественных исследователей остается открытой и весьма актуальной как для теоретического, так и для эмпирического изучения. Аналитический обзор научных публикаций, рассматривающих природу эмоционального выгорания, убедительно доказывает, что многообразие подходов к пониманию данного феномена, многочисленные его определения и трактовки могут быть объединены тем, что в них выгорание рассматривается как особое психологическое образование, характеризующее негативно окрашенное, прогрессирующее состояние человека в профессиональной деятельности и его отношение к ней. Обобщение работ, выполненных в зарубежной и отечественной исследовательских традициях показывает, что не существует единого понимания природы психического выгорания, в частности по вопросам психопрофилактики негативных проявлений данного феномена в рамках профессиональной деятельности.

Вслед за Ф.Е. Василюком, впервые предложившим считать эмоциональное выгорание в качестве дезадаптивного механизма системы психозащиты личности [1], В.В. Бойко также стал аналогично определять данный феномен [2]. Исходя из того, что эмоциональное выгорание, как и психологическая защита, возникает в результате постоянного действия острых и хронических стрессогенных ситуаций и способствует снижению травмирующих личность переживаний, редукции тревоги, а также позволяет нейтрализовать состояние эмоциональной напряженности, следует, что выгорание является защитным механизмом человеческой психики. Систематизации имеющихся теоретических представлений о психозащитном поведении и экспериментальных исследований психического выгорания позволяет сформулировать предположение о том, что эмоциональное выгорание в педагогической деятельности представляет собой сложное структурное, динамичное образование, формирующееся как специфически дезадаптивный механизм психологической защиты в ответ на пролонгированное воздействие и негативное влияние психогенной профессиональной среды [3, 4].

В конце XX века феномен выгорания в профессиональной деятельности получил статус общепризнанного, а его многочисленные негативные

\footnotetext{
${ }^{1}$ Статья подготовлена в рамках государственного задания Минобрнауки РФ № 27.7237.2017/БЧ «Моделирование системы непрерывного педагогического образования в условиях стандартизации профессиональной деятельности».
} 
последствия были научно описаны в работах известных специалистов в данной области, работодатели во многих странах стали осуществлять корпоративную политику, которая была ориентирована на профилактику переутомления и восстановление психологических ресурсов персонала. Исследования, проведенные сотрудниками американской компании «ReliaStar Insurance Company of Minneapolis», убедительно доказали, что профилактические программы, основное содержание которых направлено на создание психологически комфортной среды и сбалансированных условий на рабочем месте, позволяют предупредить эмоциональное выгорание у персонала компании. Вместе с тем в настоящее время можно обозначить ограниченное число публикаций, большей частью зарубежных (J. Poulin, C. Walter, B. Buunk, V. Hoorens, H. Freudenberger, Н.Е. Водопьянова), посвященных описанию результативности тренинговых и психотерапевтических программ по предупреждению профессионального выгорания [5-8]. В большинстве случаев на основании данных, представленных в этих программах, довольно сложно сделать однозначные выводы об их эффективности, поскольку в исследованиях используются различные выборочные совокупности, временные рамки, процедуры, инструменты измерения и методы обучения и коррекции. Поэтому стоит согласиться с Н.Е. Водопьяновой и Е.С. Старченковой, считающими: «создание профилактических и «обновляющих» программ с целью помочь «выгорающим» работникам - актуальное и очень перспективное дело» [8, с. 251]. Несмотря на то, что на сегодняшний день причины и проявления данного явления благодаря исследованиям В.Е. Орла, C. Maslach, S. Jackson и других ученых описаны достаточно подробно, противоречивым и неполным остается вопрос о психопрофилактике этого состояния. В частности, в имеющихся представлениях считается, что наиболее эффективным способом борьбы с эмоциональным выгоранием является предупреждение его возникновения, то есть профилактика, осуществляемая как на этапе обучения специалиста, так и в ходе его профессиональной деятельности $[9,10]$.

В рамках ресурсных концепций стресса, представленных в работах R. Lazarus, L. Pearlin, S. Folkman, S. Hobfoll, K. Schuler и др., вполне отчетливо обозначено, что практическая помощь работникам педагогических учреждений, подверженным профессиональному выгоранию, должна опираться на личностные, поведенческие и социальные ресурсы. Вполне очевидно, что она будет иметь положительный эффект, если осуществляется по нескольким направлениям, главным и наиболее действенным из которых выступают профилактика, работа с психологическими организационными ресурсами. Отсюда можно сделать заключение, что профилактическую работу по предупреждению риска профессионального выгорания у педагогических работников необходимо организовывать на уровне образовательного учреждения в целом. При этом она должна удовлетворять ряду психологопедагогических условий. К их числу относятся развитие здоровой атмосферы в педагогическом коллективе, профессиональная и административная поддержка, четкость должностных обязанностей, прозрачная и справедливая система поощрений и санкций, отсутствие дискриминации по признакам возраста, пола, национальности и многое другое.

Другое направление профессиональной помощи подверженным выгоранию педагогам - психопрофилактика, психологическая помощь, направленная на восстановление психоэмоциональных ресурсов, копинг (преодоление) негативных последствий профессиональных стрессов. Этому способствуют различные виды социально-психологической поддержки, реабилитационные и мотивационные тренинги, психокоррекционные и психотерапевтические программы, восполняющие внутриличностный потенциал работников педагогических организаций $[11,12]$.

Общими целями и одновременно условиями профилактики эмоционального выгорания является психологическая поддержка педагогических работников в осознании дезадаптивных форм собственного поведения, развитие личностных копинг-стратегий и личностно-средовых ресурсов преодоления профессионального стресса, приспособление к требованиям среды или трансформирование дезадаптивных форм поведения на адаптивные. Обязательным условием выступает привлечение педагогов к работе, как в краткосрочных, так и в долгосрочных психопрофилактических и реабилитационных программах «Антивыгорание», а также возможность получения помощи от социально-поддерживающего окружения. Актуальность разработки «антивыгорающих» программ обусловлена широкомасштабностью этого явления и наличием большого перечня негативных последствий, сопутствующих педагогической деятельности: высокая текучесть кадров и большие потери кадрового потенциала, снижение производительности и трудовой мотивации, утрата творческой активности и инициативности. Для иллюстрации этого положения можно привести высказывание стресс-менеджера уже упомянутой выше компании «ReliaStar Insurance Company of Minneapolis»: «Мы осознаем, насколько опасно и 
угрожающе иметь людей, работающих в состоянии выгорания. Скоро появление на работе в состоянии выгорания будет расцениваться как нарушение профессиональной этики» [8, с. 228].

Современное антивыгорающее обучение педагогов должно опираться на ряд следующих концептуальных положений: в частности, еще на начальных стадиях профессионального становления со студентами и молодыми специалистами необходимо проводить целенаправленную работу по развитию умений управлять своим эмоциональным состоянием, справляться с профессиональным стрессом. В рамках гипотезы N. Gamesy и M. Patter о превентивных буферах, которые способствуют снижению чувствительности к стрессу и развитию адаптивного копинг-поведения, можно полагать, что формирование профессионала, обладающего стресс-толерантными качествами, может быть направлено в первую очередь на развитие адаптивных копинг-стратегий [13]. Для проверки этого предположения нами был осуществлен формирующий эксперимент, включающий две психокоррекционные программы «Антивыгорание», направленные на превенцию и на редукцию эмоционального выгорания в профессиональной деятельности педагогических работников. Первая программа - превентивная - была ориентирована на обучение группы педагогов умениям психической саморегуляции, на развитие у них специальных навыков копинга - преодоления стресса и ответных реакций на стресс-факторы профессиональной деятельности и организационной среды. Другие существенные элементы данного направления - обучение и активное применение методов психологической разгрузки, снижение психоэмоциональной напряженности, купирование нежелательных симптомов стресса.

В качестве формирующего фактора во второй - реабилитационной - программе выступил комплекс специальных занятий, проводимых по типу балинтовской группы [14]. При работе в реабилитационной группе ведущий сосредотачивает участников на экзистенциальной значимости для них совершаемой работы, на выявлении причин, приведших к выбору педагогической деятельности. Значимым направлением реабилитационной программы по редукции и снижению риска выгорания является воздействие на когнитивную оценку, касающуюся собственных возможностей педагогов (умений, способностей, личностных ресурсов и др.) и готовности к совладанию с профессионально трудными ситуациями, формирование позитивного мышления и когнитивное переструктурирование профессиональных проблем.
Для осуществления формирующего эксперимента из числа педагогических работников (школьных учителей, преподавателей вузов, педагоговпсихологов, студентов-педагогов и др.), постоянно проживающих на территории Сибирского федерального округа (Республика Бурятия, Иркутская область, Томская область), принявших участие в диагностическом исследовании ( $\mathrm{n}=350)$, было задействовано 36 испытуемых, образовавших две экспериментальные (I, II) и одну контрольную (III) группы (по 12 человек в каждой). В сравнительном исследовании контрольная группа имела половозрастные и другие социально-демографические и формальные характеристики, сходные с аналогичными у испытуемых из экспериментальных групп, работающих по превентивной и реабилитационной программам. На протяжении 2016-2018 гг. была проведена процедура экспериментального исследования, состоящего их четырех последовательных этапов. На первом и третьем этапах для входной и выходной психодиагностики использовался комплекс валидных и надежных психодиагностических методик, включающий личностные опросники, адекватные задачам проводимого исследования:

1) «Профессиональное выгорание» (MBI), разработанный C. Maslach (в адаптации H.E. Водопьяновой);

2) «Индекс жизненного стиля» (LSI), разработанный R. Plutchik и H. Kellerman (в адаптации Е.Б. Клубовой и др.);

3) «Индикатор копинг-стратегий» (CSI), разработанный J. Amirkhan (в адаптации B.M. Ялтонского, Н.А. Сироты).

Все испытуемые, принявшие участие в работе формирующего эксперимента (второй этап), имели исходный высокий уровень эмоционального выгорания, измеренный с помощью методики МBI. Статистически значимых различий между психодиагностическими показателями экспериментальных и контрольной групп на начальном этапе не обнаружено ( $<$ < 0,05) (все статистические данные, представленные в статье, соответствуют уровню значимости 0,05). Спустя один месяц после окончания работы превентивной и реабилитационной программ, длившихся в течение трех лет, результаты повторного тестирования были подвергнуты сравнительному анализу при помощи процедуры однофакторного дисперсионного анализа ANOVA (по Фишеру). Соотнесение полученных результатов продемонстрировало статистически значимое уменьшение показателей по ряду психологических характеристик, отражающих снижение уровней психоэмоционального напряжения и про- 
фессионального выгорания в экспериментальных группах. Результаты измерений (математическое ожидание Мј) по субшкалам методики МBI («Психоэмоциональное истощение», «Деперсонализация», «Профессиональная редукция») отражают статистически значимые изменения со стороны выраженности эмоционального выгорания, вызванные воздействием мероприятий превентивной и реабилитационной программ.

Осуществление процедуры дисперсионного анализа позволило обнаружить, что показатели редукции психоэмоционального истощения в экспериментальных группах превышают аналогичные в контрольной группе. При этом наибольшие позитивные изменения произошли в экспериментальной реабилитационной группе $(\mathrm{Mj}(\mathrm{II})=22,31)$. Несколько меньшая эффективность экспериментального воздействия по показателю «Психоэмоциональное истощение» отмечена в экспериментальной превентивной группе $(\mathrm{Mj}(\mathrm{I})=25,43)$. Также в экспериментальных группах достоверно больше изменений обнаружено в сторону снижения проявлений деперсонализации по сравнению с контрольной группой: $(\mathrm{Mj}(\mathrm{I})=26,9$; $\mathrm{Mj}(\mathrm{II})=25,27)$. Доля сдвигов в сторону увеличения показателей «Профессиональная редукция», свидетельствующих об уменьшении выраженности редукции профессиональных достижений, также отражает наибольшую эффективность экспериментальной реабилитационной группы $(\mathrm{Mj}(\mathrm{I})=19,29$; Mj(II $=23,32)$. В целом же на фоне показателей психоэмоционального истощения и профессиональной редукции показатели деперсонализации, выступающие установочным компонентом эмоционального выгорания, проявляющегося в профессиональной деятельности деформацией отношений с другими людьми, полной или частичной утратой интереса к субъекту профессиональной деятельности, характеризуются наименьшими изменениями. Вполне вероятно, что это обусловлено изменениями отношений к другим и жизненной позицией личности. Максимальная чувствительность к влиянию экспериментальных психокоррекционных программ «Антивыгорание» была обнаружена по компоненту «Профессиональная редукция» в отношении отрицательных установок в выполнении профессиональных обязанностей. При этом динамика изменений показателей профессионального выгорания по всем трем субшкалам опросника МBI у испытуемых из контрольной группы на протяжении всего периода эксперимента статистически достоверных изменений не претерпела.

Таким образом, подытоживая результаты апробации экспериментальных программ «Анти- выгорание», можно констатировать снижение профессионального выгорания по всем трем вышеобозначенным компонентам. Выраженность проявлений выгорания в контрольной группе осталось практически неизменным. При апробации обеих программ отмечена эффективность реабилитационной программы, основанной на принципах работы балинтовских групп. Как известно, балинтовская группа выступает инструментом психологического сопровождения специалистов «помогающих» профессий в их личной и профессиональной практической деятельности. Работа балинтовской группы, образованной педагогическими работниками, фиксируется на взаимодействии педагога с учащимися и их родителями, а также с вышестоящим руководством и коллегами. Проведенная с помощью теста LSI диагностика наглядно продемонстрировала отчетливое снижение суммарной степени напряженности психологической защиты у испытуемых, принявших участие в работе экспериментальной группы, действующей в рамках психотерапевтических принципов, предложенных M. Balint. В частности, доэкспериментальный показатель степени напряженности защиты (Mj) во всех трех группах отражает достаточно высокую напряженность защитных механизмов у испытуемых $(\operatorname{Mj}(\mathrm{I})=43,49 ; \operatorname{Mj}(\mathrm{II})=43,91 ; \operatorname{Mj}(\mathrm{III})=43,0)$. Спустя месяц после окончания регулярных ежемесячных занятий, проводимых в течение года в обеих экспериментальных группах, обнаружены статистически достоверные изменения по анализируемому показателю $(\mathrm{Mj}(\mathrm{I})=36,78 ; \mathrm{Mj}(\mathrm{II})=29,55)$, в то время как в контрольной группе такие изменения между доэкспериментальным и послеэкспериментальным показателями минимальны $(\mathrm{Mj}(\mathrm{III})=43,26)$.

Положительный итог формирующего эксперимента в экспериментальных группах проявился снижением сверхнапряженного функционирования психозащитных механизмов психологической защиты, редукцией психоэмоционального напряжения, снижением показателей личностной тревожности, изменением реального отношения испытуемых к действительности, их объективного отношения к самим себе. Вместе с тем обнаружилось, что эмоциональная устойчивость, понимание своих внутриличностных проблем тесно связаны с участием испытуемых в работе реабилитационной балинтовской группы, выявившей себя в качестве эффективного способа преодоления профессионального стресса и выгорания, по сравнению с превентивной группой, направленной на снижение психоэмоционального напряжения. Вероятно, это обусловлено тем, что балинтовские группы делают 
возможным достаточно эффективное устранение бессознательных защитных «пятен» в профессиональном самосознании, снижение значимости причин, вызывающих психотравмирующую ситуацию, смягчение многих ригидных стереотипов в педагогическом взаимодействии, оптимизацию педагогического общения. Можно считать, что именно балинтовская группа способна в значительной степени - деликатно и нетравматично - представлять необходимую поддержку, высвечивать и санировать проблемные зоны специалистов «помогающих» и социономических профессий. Снижения сверхнапряженного использования базисных механизмов психологической защиты в экспериментальной реабилитационной группе удалось достичь благодаря тому, что балинтовские группы позволяют их участникам преодолеть профессиональную разобщенность многих педагогов», успешнее достигать сотрудничества. Следовательно, важным психолого-педагогическим условием профилактики эмоционального выгорания на рабочем месте становится поддержка коллег по работе.

Другим не менее значимым психолого-педагогическим условием и одновременно направлением реабилитационной программы «Антивыгорание» в рамках формирующего эксперимента выступило обучение педагогов навыкам использования адаптивных личностных копинг-стратегий преодоления проблемных ситуаций, возникающих на рабочем месте. Основная задача заключалась в том, чтобы выработать у педагогов навыки конструктивных стратегий совладания (в частности, проблемно-ориентированную копинг-стратегию «Разрешение проблем» в трудных педагогических ситуациях), которые имеют доступное решение, а эмоционально-ориентированную копинг-стратегию «Избегание проблем» - в том случае, если адекватное разрешение актуальной проблемы представляется невозможным. В ходе апробации обеих программ (превентивной и реабилитационной) проявилось преимущество активных, конструктивных стратегий совладания, например, таких как «Разрешение проблем» и «Поиск социальной поддержки», по сравнению с пассивными техниками преодоления («Избегание проблем»).

Участники экспериментальных групп посредством обучения навыкам психической саморегуляции, выполнения различных упражнений на стрессоустойчивость, а также в ходе обсуждений в балинтовской группе имели возможность отработать эффективные копинг-стратегии и осознать их позитивное воздействие на профессиональное самочувствие и качество жизни в целом. Положительный эффект от программ управления стрессом и выгоранием на рабочем месте отразился в результатах посттестирования базисных копинг-стратегий с использованием опросника CSI. Различия по уровню выраженности базисных копинг-стратегий «Разрешение проблем» $(\mathrm{Mj}(\mathrm{I})=17,89 ; \mathrm{Mj}(\mathrm{II})=20,52 ; \mathrm{Mj}(\mathrm{III})=19,33)$, «Избегание проблем» $(\mathrm{Mj}(\mathrm{I})=26,27 ; \mathrm{Mj}(\mathrm{II})=25,07$; $\mathrm{Mj}(\mathrm{III})=25,95)$ и «Поиск социальной поддержки» $(\mathrm{Mj}(\mathrm{I})=16,29 ; \mathrm{Mj}(\mathrm{II})=17,34 ; \mathrm{Mj}(\mathrm{III})=16,14)$ между контрольной и экспериментальными группами до психологического вмешательства были минимальны. Результаты сопоставления показателей «входной» психодиагностики копинг-стратегий и посттестирования продемонстрировали, что целенаправленное обучение проактивным стратегиям преодоления позволяет эффективно совладать с профессиональным стрессом посредством осознанного применения приемов конструктивного совладания.

У педагогов - участников экспериментальных групп было выявлено (по сравнению с предшествующим обучению периодом) увеличение показателей по активным копинг-стратегиям «Разрешение проблем» $(\mathrm{Mj}(\mathrm{I})=24,32 ; \mathrm{Mj}(\mathrm{II})=26,18)$ и «Поиск социальной поддержки» $(\mathrm{Mj}(\mathrm{I})=27,98 ; \mathrm{Mj}(\mathrm{II})=30,03)$ и уменьшение выраженности пассивной стратегии «Избегание проблем» $(\mathrm{Mj}(\mathrm{I})=19,19 ; \mathrm{Mj}(\mathrm{II})=21,26)$. При этом наибольшие позитивные сдвиги по показателям проблемно-ориентированных копингстратегий «Разрешение проблем» (7,23 балла) и «Поиск социальной поддержки» (12,06 баллов) произошли в реабилитационной группе по сравнению с превентивной группой (соответственно 5,04 и 11,93 балла). Это может быть объяснено тем, что в специально создаваемых, экспериментальных ситуациях тренировались навыки уверенного поведения и стимулировались внутренняя мотивация профессионального развития, самоактуализация и личностный рост.

Участники превентивной группы, направленной на снижение психоэмоционального напряжения, установление душевного равновесия, повышение оптимистичности, показали более успешные, чем участники реабилитационной группы, позиции в применении копинг-стратегии «Избегание проблем». Динамика выраженности пассивной стратегии «Избегание проблем» при одновременном увеличении задействованности активных «Разрешение проблем» и «Поиск социальной поддержки» свидетельствует в пользу позитивных сдвигов в сторону снижения ее показателей. При этом в превентивной группе «разрыв» более выражен, чем в реабилитационной (соответственно 7,28 и 4,94 балла). 
За весь период эксперимента в контрольной группе статистически достоверных изменений со стороны всех трех базисных копинг-стратегий не обнаружено: «Разрешение проблем» (до начала эксперимента $\mathrm{Mj}(\mathrm{III})=19,07$; после окончания эксперимента $\mathrm{Mj}(\mathrm{III})=18,50)$, «Избегание проблем» (до начала эксперимента $\mathrm{Mj}(\mathrm{III})=26,0$, после окончания эксперимента $\mathrm{Mj}(\mathrm{III})=25,84)$, «Поиск социальной поддержки» (до начала эксперимента $\mathrm{Mj}(\mathrm{III})=16,11$; после окончания эксперимента $\mathrm{Mj}(\mathrm{III})=16,28)$. Отсутствие динамики у показателей выраженности базисных копинг-стратегий в контрольной группе при наличии статистически значимой разницы внутри экспериментальных групп демонстрирует психокоррекционный и психотерапевтический эффект от программ «Антивыгорание», их положительное влияние на поведенческие копинг-стратегии педагогов. Ковариационные взаимоотношения между компонентами профессионального выгорания и показателями анализируемых в формирующем эксперименте психологических конструктов совладания со стрессом показывают преимущественную результативность реабилитационной группы. Показатели выгорания, демонстрирующие позитивную динамику эмоционального самочувствия и волнений, возникающих на рабочем месте, находятся в статистически достоверной зависимости от изменений степени напряженности психологической защиты, редуцированной в ходе психокоррекционных превентивной и реабилитационной «антивыгорающих» программ.

При этом довольно высокие коэффициенты линейной корреляции у испытуемых педагогов из реабилитационной группы $(\mathrm{rxy}=0,63 ; \mathrm{rxy}=0,60)$ отражают действенное влияние балинтовской группы на степень напряженности психологической защиты и сопряженного с ней профессионального выгорания по сравнению с превентивной $(\mathrm{rxy}=0,46 ; \mathrm{rxy}=0,44)$, направленной на редукцию профессионального стресса группой. Определенными соотношениями характеризуются коэффициенты линейной корреляции компонентов профессионального выгорания и интегративного показателя копинг-поведения, полученного путем суммирования субшкал опросника MBI: в реабилитационной группе их абсолютные значения $(\mathrm{rxy}=-0,53 ; \mathrm{rxy}=-0,49)$ выше, чем в превентивной (rxy $=-0,44 ; \mathrm{rxy}=-0,29)$. В обеих группах коэффициенты имеют прямо противоположную, отрицательную направленность корреляционной связи, тем самым отражая позитивное влияние выраженного совладающего поведения на редукцию выгорания. Результаты математико-статистических расчетов позволяют сделать однозначный вывод: снижение выраженности выгорающего поведения на рабочем месте у испытуемых из психокоррекционных превентивной и реабилитационной групп обусловлено активным участием в экспериментальных программах «Антивыгорание». Представленный анализ ковариационных отношений и сопоставление коэффициентов корреляции, полученных в превентивной и реабилитационной группах между компонентами профессионального выгорания и показателями анализируемых в формирующем эксперименте психологических конструктов, позволяет отдать предпочтение балинтовской группе в качестве эффективного методического инструмента, выступающего базисным основанием психопрофилактических программ по работе с выгоревшими педагогическими работниками.

Следовательно, можно считать, что опыт проведения специализированных экспериментальных программ «Антивыгорание» свидетельствует о реальной возможности психолого-педагогического сопровождения педагогов, переживающих выгорание в профессиональной деятельности. Здесь вполне очевиден вывод о том, что работники, применяющие адаптивные стратегии преодоления проблемных ситуаций, более толерантны и лучше подготовлены к «переживанию» эмоционального стресса; они более результативно справляются с различными профессиональными проблемами и с их негативными последствиями, приводящими к картине выгорания. Кроме того, результаты экспериментальных исследований свидетельствуют: выраженные проявления профессионального выгорания тесно взаимосвязаны с напряженной психологической защитой и пассивными стратегиями совладания. Соответственно, психологическим условием редукции выгорания выступает снижение уровня неосознаваемого защитного поведения путем интериоризации осознанных зрелых копинг-механизмов и формирования паттернов адаптированных взаимоотношений с субъектами профессиональной деятельности. С целью профилактики и редукции профессионального выгорания целесообразно осуществлять работу как постоянных, так и краткосрочных превентивных и реабилитационных программ, адресованных педагогическим работникам. Вместе с тем стоит сделать вывод, что более эффективными и более предпочтительными следует считать программы, направленные на формирование компонентов активного копинг-поведения, работающие в рамках активного психотерапевтического подхода, в частности балинтовские группы. Таким образом, результаты эмпирического исследования психолого-педагоги- 
ческих условий, обеспечивающих профилактику и преодоление проявлений эмоционального выгорания в педагогической деятельности, позволяют считать таковыми осуществление своевременной диагностики, выявляющей изменения уровня выраженности эмоционального выгорания и индивидуально-психологических характеристик лич- ности, а также определение стратегий преодоления выгорания (неосознаваемые механизмы психологической защиты, осознанные копинг-стратегии совладения с жизненными и профессиональными трудностями), разработка и реализация релевантных психопрофилактических программ и технологий преодоления профессионального выгорания.

\section{Библиографический список}

1. Василюк Ф. Е. Психология переживания: Анализ преодоления критических ситуаций. М.: МГУ, 1984. 200 с.

2. Бойко В. В. Синдром эмоционального выгорания в профессиональном общении. СПб: Сударыня, 1999. 32 с.

3. Корытова Г. С. Эмоциональное выгорание как проявление защитного поведения в профессиональной деятельности // Фундаментальные исследования. 2005. № 4. С. 29-32.

4. Корытова Г. С. Совладание с психологическим стрессом в профессиональной педагогической деятельности: монография. Иркутск: Иркутский государственный педагогический университет, 2009. 363 с.

5. Poulin J., Walter C. Social worker burnout: a longitudinal study // Research and Abstracts. 1993. V. 29. Is. 4. P. $5-11$.

6. Buunk B., Hoorens V. Social support and stress // British journal of clinical psychology. 1992. V. 31. P. $445-457$.

7. Freudenberger H. Staff burn-out // Journal of social issues. 1974. V. 30. P. 159-165.

8. Водопьянова Н. Е., Старченкова Е. С. Синдром выгорания: диагностика и профилактика. СПб.: Питер, 2005. 336 c.

9. Орел В. Е. Синдром психического выгорания личности. М.: Институт психологии РАН, 2005. 329 с.

10. Maslach C., Jackson S. The measurement of experienced burnout // Journal of Occupational Behavior. 1981. V. 2. P. $99-113$

11. Форманюк Т. В. Синдром «эмоционального сгорания» как показатель профессиональной дезадаптации учителя // Вопросы психологии. 1994. № 6. С. 57-64.

12. Корытова Г. С., Никифорова Н. А. Профессиональное становление личности педагога: проблемное поле и концептуальные модели // Вестник Томского государственного педагогического университета. 2015. № 1 (154). C. 9-15.

13. Сирота Н. А., Ялтонский В. М. Профилактика наркомании у подростков: от теории к практике. М.: Генезис, 2001. 216 c.

14. Винокур В. А., Кремлева О. В. Балинтовские группы и супервизия в подготовке специалистов, работающих с людьми. СПб.: Санкт-Петербургская академия МВД России, 1998. 83 с. 